Article

\title{
A Novel and Efficient Metal Oxide Fluoride Absorbent for Drinking Water Safety and Sustainable Development
}

\author{
Changjuan Dong ${ }^{1,2}\left(\right.$, Xiaomei Wu ${ }^{1, *}$, Zhanyi Gao ${ }^{1, *}$, Peiling Yang ${ }^{2}$ and Mohd Yawar Ali Khan ${ }^{3}$ \\ 1 State Key Laboratory of Simulation and Regulation of Water Cycle in River Basin, \\ China Institute of Water Resources and Hydropower Research, Beijing 100038, China; \\ Emily_ssy@outlook.com \\ 2 College of Water Resources and Civil Engineering, China Agricultural University, Beijing 100083, China; \\ yang-pl@163.com \\ 3 Department of Hydrogeology, King Abdulaziz University, Jeddah 21589, Saudi Arabia; \\ yawar.gr44@gmail.com \\ * Correspondence: wuxm@iwhr.com (X.W.); zhanyi_gao@126.com (Z.G.); \\ Tel.: +86-010-68786961 (X.W.); +86-010-63204693 (Z.G.)
}

check for updates

Citation: Dong, C.; Wu, X.; Gao, Z.; Yang, P.; Khan, M.Y.A. A Novel and Efficient Metal Oxide Fluoride Absorbent for Drinking Water Safety and Sustainable Development. Sustainability 2021, 13, 883. https:// doi.org/10.3390/su13020883

Received: 25 November 2020 Accepted: 13 January 2021

Published: 17 January 2021

Publisher's Note: MDPI stays neutral with regard to jurisdictional clai$\mathrm{ms}$ in published maps and institutional affiliations.

Copyright: (C) 2021 by the authors. Licensee MDPI, Basel, Switzerland. This article is an open access article distributed under the terms and conditions of the Creative Commons Attribution (CC BY) license (https:// creativecommons.org/licenses/by/ $4.0 /)$.

\begin{abstract}
Inefficient and non-environmentally friendly absorbent production can lead to much resource waste and go against low carbon and sustainable development. A novel and efficient $\mathrm{Mg}-\mathrm{Fe}-\mathrm{Ce}$ (MFC) complex metal oxide absorbent of fluoride ion $\left(\mathrm{F}^{-}\right)$removal was proposed for safe, environmentally friendly, and sustainable drinking water management. A series of optimization and preparation processes for the adsorbent and batch experiments (e.g., effects of solution $\mathrm{pH}$, adsorption kinetics, adsorption isotherms, effects of coexisting anions, as well as surface properties tests) were carried out to analyze the characteristics of the adsorbent. The results indicated that optimum removal of $\mathrm{F}^{-}$occurred in a $\mathrm{pH}$ range of $4-5.5$, and higher adsorption performances also happened under neutral $\mathrm{pH}$ conditions. The kinetic data under 10 and $50 \mathrm{mg} \cdot \mathrm{g}^{-1}$ were found to be suitable for the pseudo-second-order adsorption rate model, and the two-site Langmuir model was ideal for adsorption isotherm data as compared to the one-site Langmuir model. According to the two-site Langmuir model, the maximum adsorption capacity calculated at $\mathrm{pH} 7.0 \pm 0.2$ was $204 \mathrm{mg} \cdot \mathrm{g}^{-1}$. The adsorption of $\mathrm{F}^{-}$was not affected by the presence of sulfate $\left(\mathrm{SO}_{4}{ }^{2-}\right)$, nitrate $\left(\mathrm{NO}_{3}{ }^{-}\right)$, and chloride $\left(\mathrm{Cl}^{-}\right)$, which was suitable for practical applications in drinking water with high $\mathrm{F}^{-}$ concentration. The MFC adsorbent has an amorphous structure, and there was an exchange reaction between $\mathrm{OH}^{-}$and $\mathrm{F}^{-}$. The novel MFC adsorbent was proven to have higher efficiency, better economy, and environmental sustainability, and be more environmentally friendly.
\end{abstract}

Keywords: drinking water; fluoride adsorption; sustainability; tri-metal oxide absorbent

\section{Introduction}

Drinking water safety and sustainability, closely bound with people's lives, have always attracted the most public attention among various the human health-related issues. Fluoride pollution is one of the most common challenges in drinking water safety, and excessive fluoride intake can affect the human body and lead to severe health problems, such as fluorosis and osteoporosis [1-3]. It was reported that about 200 million people in 25 countries around the world are under the threat of the fluorosis [4]. In addition, there are nearly 45 million people suffering the negative effects of high fluoride drinking water with fluoride ion $\left(\mathrm{F}^{-}\right)$concentrations of more than $1.0 \mathrm{mg} \cdot \mathrm{L}^{-1}$ in China, mainly distributed in the north, northwest, and east of China, with $80 \%$ in the northern areas of the Yangtze River, especially in rural areas [5]. Therefore, it is an urgency to search for an effective measure to remove fluoride not only for drinking water safety and sustainability but also for the victory of a poverty alleviation plan. 
Numerous efforts have been devoted to effective $\mathrm{F}^{-}$removal technology development [6-8], such as precipitation [9], electrocagulation [10], membranes [11], ion exchange [12-14], and adsorption [15-18]. For example, Shen et al. (2003) proposed a treatment measure through the combined electrocoagulation and electroflotation process to remove fluoride ions and found that the anions had a negative effect on fluoride removal efficiency [10]. Robshaw et al. (2019) developed a novel ligand-exchange sorbent with chelating resin Purolite ${ }^{\circledR}$ S950+ loaded with lanthanum (La) ions, and it possessed a greater uptake (maximum defluoridation capacity of $187 \pm 15 \mathrm{mg} \cdot \mathrm{g}^{-1}$ ) than previously reported similar metal-loaded resins [9]. Singh et al. (2020) developed a zirconium impregnated hybrid anion exchange resin (HAIX-Zr) for fluoride removal from contaminated groundwater and evaluated fluoride removal performances. A higher defluoridation capacity $\left(12.0 \mathrm{mg} \cdot \mathrm{g}^{-1}\right)$ and a possible fluoride removal mechanism $\left(\mathrm{OH}^{-}\right.$with $\mathrm{F}^{-}$exchange $)$ were found [14]. Compared with these technologies, adsorption is considered the most efficient acceptable technology due to its simple process, easy operation, and lack of pollution, and has been widely investigated in fluoride removal studies [19-21]. For example, Bansiwal et al. (2010) synthesized copper oxide coated alumina to enhance water defluoridation with a higher adsorption capacity $\left(7.22 \mathrm{mg} \cdot \mathrm{g}^{-1}\right)$ than unmodified activated alumina $\left(2.232 \mathrm{mg} \cdot \mathrm{g}^{-1}\right)$ [22]. Dong and Wang (2016) developed a novel lanthanum-loaded magnetic cationic hydrogel (MCH-La) for fluoride adsorption from drinking water with a maximum adsorption capacity $\left(136.78 \mathrm{mg} \cdot \mathrm{g}^{-1}\right)$ and bigger adsorption capacity $(70 \%$ from the second to fifth recycles) [23]. Thathsara et al. (2018) synthesized a novel tri-metal composite (FeLa-Ce) for the removal of excess fluoride in aqueous media with a maximum adsorption capacity (303.03 $\mathrm{mg} \cdot \mathrm{g}^{-1}$ at $\left.\mathrm{pH} 4.00\right)$ and excellent regeneration (96.13\% desorption) and reusability [24]. Huang et al. (2020) proposed an $\mathrm{Al}(\mathrm{OH})_{3}$-hydroxyapatite nanosheet ( $\mathrm{Al}$ $(\mathrm{OH})_{3}$-nHAP) for fluoride sorption from an aqueous solution with a higher defluoridation capacity (194.2 mg. ${ }^{-1}$ in neutral condition at $\left.318 \mathrm{~K}\right)$ and a higher removal efficiency of a regenerated $\mathrm{Al}(\mathrm{OH})_{3}$-nHAP nanosheet (81.32\%) [25]. Kumar et al. (2020) advanced both activated alumina (AA) and grinded activated alumina (GAA) for adsorption potential by batch experiments for different contact time, $\mathrm{pH}$, fluoride concentration, and adsorbent dose for fluoride adsorption [26]. From the above analysis, activated alumina is a popular treatment technology for $\mathrm{F}^{-}$removal due to its availability and low cost, and there are some limitation on frequent regeneration with aluminum sulfate under a lower adsorption capacity at a neutral $\mathrm{pH}$ (5-6) [27]. Furthermore, residual alumina in treated water may cause adverse health effects due to its characteristics and 5-10\% loss of adsorbency on regeneration [28].

Faced with the above difficulties, multivalent metal ( $\mathrm{Mg}, \mathrm{Al}, \mathrm{Fe}, \mathrm{La}, \mathrm{Zr})$ oxides and hydroxides mixed with rare earth metals have been used for obtaining higher $\mathrm{F}^{-}$removal capacities [29-37]. This is because rare earth metals are possessed with a strong affinity for fluoride treatment [38-40].

For example, Chi et al. (2017) proposed a novel magnesium-aluminum-cerium trimetallic composite adsorbent with a higher removal efficiency over a wide range of $\mathrm{pH}$ (3.0-10.0) and a higher adsorption capacity for fluoride (e.g., $124.9 \mathrm{mg} \cdot \mathrm{g}^{-1}$ ) [33]. Adak et al. (2017) developed an adsorbent with Al (III) - Fe (III) - $\mathrm{La}$ (III) trimetallic oxide with $99.9 \%$ fluoride removal efficiency under the condition of $\mathrm{pH} 7.0$ at an adsorbent dose of $0.3 \mathrm{~g} \cdot 100 \mathrm{~mL}^{-1}$ during a contact time of $60 \mathrm{~min}$ [41]. From the previous studies, rare earth metals are commonly expensive and the optimum $\mathrm{pH}$ was in the acidic range. However, high fluorine drinking water is mostly alkaline. This restricts the application of the adsorbent to practical drinking water defluoridation.

Therefore, in order to search for a safe, economic, and environmentally friendly measure for practical engineering, the aim of this study was to propose a novel $\mathrm{Mg}$-Fe-Ce (MFC) composite absorbent. A series of experiments of fluoride adsorption was designed to explore the characterization and mechanisms of the adsorbents, including (1) $\mathrm{pH}$ influence experiments for optimal $\mathrm{pH}$ adsorption, (2) adsorption kinetics experiments for kinetics characterization, (3) adsorption isotherm experiments for isotherm characterization, (4) 
anionic influence experiments for the anionic environmental restriction of the adsorbent, and (5) X-ray diffraction (XRD) analysis and Fourier transform infrared (FTIR) spectroscopy for surface properties. The proposed MFC composite absorbent possesses the highest $\mathrm{F}^{-}$ removal capacity, lowest cost, and most environmental sustainability, and is suitable for practical applications in drinking water with a high $\mathrm{F}^{-}$concentration.

\section{Materials and Methods}

\subsection{Materials}

All chemicals and reagents $\left(\mathrm{MgCl}_{2} \cdot 6 \mathrm{H}_{2} \mathrm{O}, \mathrm{FeSO}_{4} \cdot 7 \mathrm{H}_{2} \mathrm{O}, \mathrm{Ce}\left(\mathrm{SO}_{4}\right)_{2} \cdot 4 \mathrm{H}_{2} \mathrm{O}, \mathrm{Al}_{2}(\mathrm{SO} 4)_{3}\right.$, $\mathrm{ZnSO}_{4} \cdot 7 \mathrm{H}_{2} \mathrm{O} \mathrm{NaF}, \mathrm{HCl}, \mathrm{NaOH}, \mathrm{Na}_{2} \mathrm{SO}_{4}, \mathrm{NaCl}, \mathrm{NaNO}_{3}, \mathrm{Na}_{2} \mathrm{SO}_{4}$ ) were of analytical grade and were mainly purchased from Chemical Engineering Company in Beijing, China; Xilong Scientific Co., Ltd.; Tianjin Guangfu Fine Chemical Research Institute; and Beijing Yili Fine Chemicals Co., Ltd. All solutions were prepared with deionized water (Total organic carbon (TOC) of less than $50 \mathrm{ppb}$, resistivity of more than $1.0 \mathrm{M} \Omega \cdot \mathrm{cm}$, and silicide concentration of less than $100 \mathrm{ppb}$ ) at room temperature. The $\mathrm{pH}$ of the solution was measured using a $\mathrm{pH}$ meter (HM-14P, TOA, Kobe, Japan). $\mathrm{F}^{-}$concentrations were analyzed with a fluoride selective electrode connected to an ion meter (IM-40S, TOA, Kobe, Japan). The dried adsorbent powder was analyzed by X-ray diffractometer (XRD, Bruker D8 Advance, Karlsruhe, Germany) and Fourier Transform Infrared Spectrometer (FTIR, Nicolet 750 model, Madison, USA ).

\subsection{Methods}

In this study, a typical adsorbent preparation and characterization test process was proposed for $\mathrm{F}^{-}$removal from practical drinking water engineering with high $\mathrm{F}^{-}$concentrations. It included three steps, such as optimization of the adsorbent, preparation of the adsorbent, and experiments for adsorbent characterization. The first step was optimization of the metal components, the solution $\mathrm{pH}$, the preparation method, and the calcination temperature with the objective of acquiring an adsorbent with the highest adsorption capacity. The second step was controlling the preparation condition, such as dried temperature, calcined temperature, and time, to guarantee the adsorbent preparation. The third step was carrying out the adsorption experiments and surface properties tests in order to investigate the characterization of the adsorbent. The sketch map for the process is shown in Figure 1.

\subsubsection{Optimization and Preparation of the Adsorbent}

To prepare the optimal adsorbent for $\mathrm{F}^{-}$removal, a series of experiments to analyze the metal composition of the adsorbent, search for the optimization method of the adsorbent preparation, investigate the best composition ratio of the adsorbent, obtain the suitable final $\mathrm{pH}$ value, and determine the best calcination temperature was carried out.

In order to investigate the effect of the different metal composition of the adsorbent, three mixed solutions were prepared. The preparation processes of $\mathrm{Mg}$-Fe-Ce, $\mathrm{Zn}-\mathrm{Al}-\mathrm{Ce}$, and $\mathrm{Zn}$-Fe-Ce adsorbent were the same. $\mathrm{MgCl}_{2} \cdot 6 \mathrm{H}_{2} \mathrm{O}, \mathrm{FeSO}_{4} \cdot 7 \mathrm{H}_{2} \mathrm{O}$ and $\mathrm{Ce}\left(\mathrm{SO}_{4}\right)_{2} \cdot 4 \mathrm{H}_{2} \mathrm{O}$ were dissolved for the mixed solution with a molar concentration ratio of $\mathrm{Mg}: \mathrm{Fe}: \mathrm{Ce}$ of 4:1:1. $\mathrm{ZnSO}_{4} \cdot 7 \mathrm{H}_{2} \mathrm{O}, \mathrm{Al}_{2}(\mathrm{SO} 4)_{3}$, and $\mathrm{Ce}\left(\mathrm{SO}_{4}\right)_{2} \cdot 4 \mathrm{H}_{2} \mathrm{O}$ were dissolved for the mixed solution with a molar concentration ratio of $\mathrm{Zn}: \mathrm{Al}: \mathrm{Ce}$ of $4: 1: 1 . \mathrm{ZnSO}_{4} \cdot 7 \mathrm{H}_{2} \mathrm{O}, \mathrm{FeSO}_{4} \cdot 7 \mathrm{H}_{2} \mathrm{O}$, and $\mathrm{Ce}\left(\mathrm{SO}_{4}\right)_{2} \cdot 4 \mathrm{H}_{2} \mathrm{O}$ were dissolved for the mixed solution with a molar concentration ratio of $\mathrm{Zn}: \mathrm{Fe}: \mathrm{Ce}$ of 4:1:1. The final $\mathrm{pH}$ of the three mixed solutions were all adjusted to 8.5 with $6 \mathrm{~mol} \cdot \mathrm{L}^{-1} \mathrm{NaOH}$. Then the three adsorbents (i.e., $\mathrm{Mg}-\mathrm{Fe}-\mathrm{Ce}, \mathrm{Zn}-\mathrm{Al}-\mathrm{Ce}$, and $\mathrm{Zn}-\mathrm{Fe}-\mathrm{Ce}$ ) were synthesized by the co-precipitation method at a calcination temperature of $600{ }^{\circ} \mathrm{C}$. 


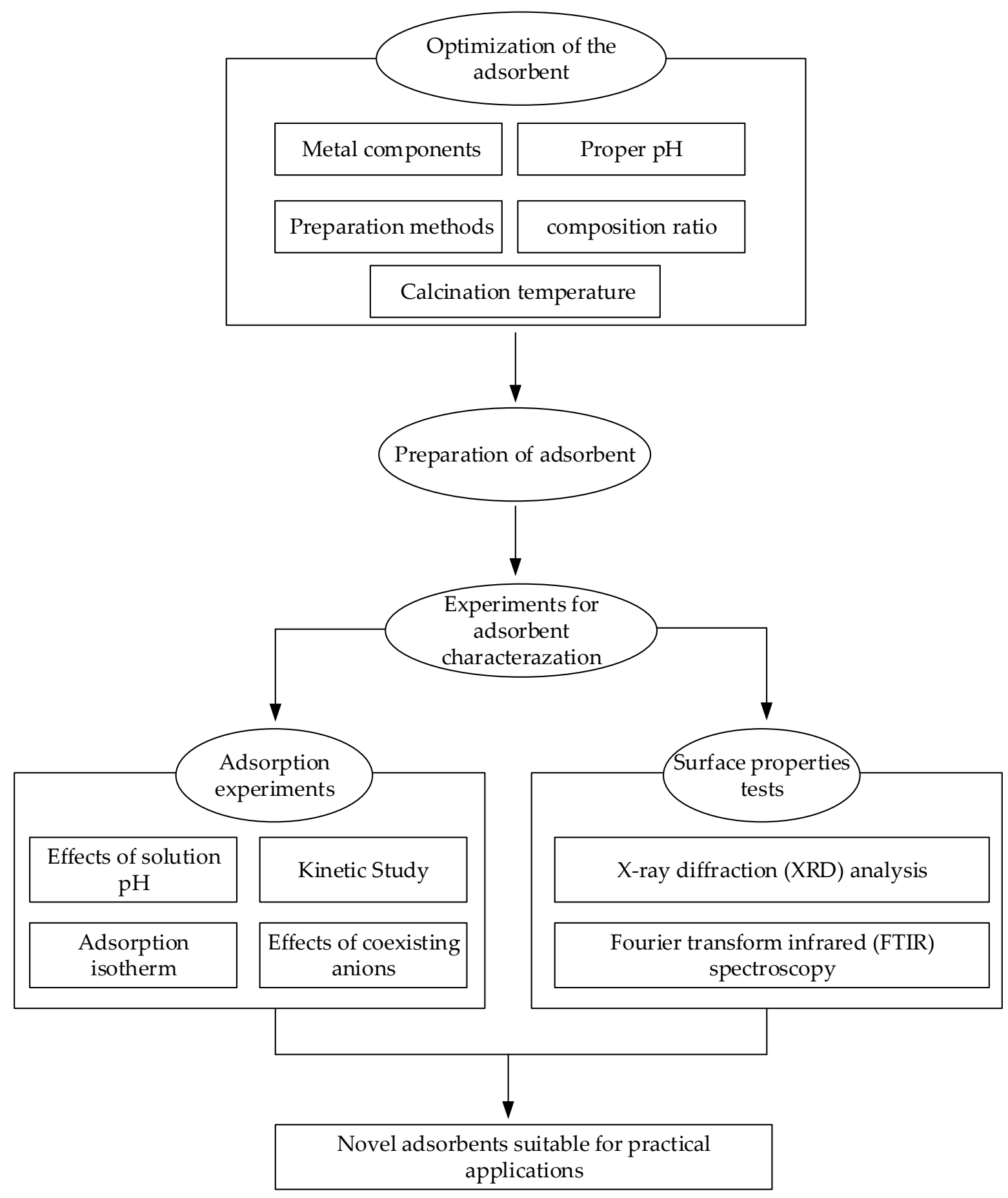

Figure 1. The sketch map of the study.

To choose the best synthetic method for the adsorbent, two synthesis methods (i.e., the co-precipitation method and hydrothermal synthesis method) were compared. The detailed co-precipitation method was (1) preparing the required experimental solution, (2) adjusting $\mathrm{pH}$ with $6 \mathrm{~mol} \cdot \mathrm{L}^{-1} \mathrm{NaOH}$ to 8.5 and keeping this $\mathrm{pH}$ more than $30 \mathrm{~min}$, (3) keeping still for more than $24 \mathrm{~h}$, (4) washing the acquired precipitate and centrifuging all the mixed solution-including precipitate and washing water, (5) drying the precipitate under $65{ }^{\circ} \mathrm{C}$ for $24 \mathrm{~h}$, and (6) calcining in the muffle furnace at $600{ }^{\circ} \mathrm{C}$. The detailed hydrothermal synthesis method was (1) preparing the required experimental solution, (2) adding the solution and $6 \mathrm{~mol} \cdot \mathrm{L}^{-1} \mathrm{NaOH}$ to the autoclave and fastening the gap, (3) 
heating for $6 \mathrm{~h}$ under $90{ }^{\circ} \mathrm{C}$, (4) sampling after cooling and exhausting, (5) washing the acquired precipitate and centrifuging all the mixed solution-including precipitate and washing water, (6) washing and drying the precipitate under $65^{\circ} \mathrm{C}$, and (7) calcining in the muffle furnace at $600{ }^{\circ} \mathrm{C}$.

To investigate the best composition ratio of the adsorbent, different $\mathrm{Mg}: \mathrm{Fe}: \mathrm{Ce}$ composition ratio solutions were prepared by the method of keeping two composition ratio invariant and the third composition variable (shown in Table 1). Then different composition ratio adsorbents were synthetized based on the solution with a different composition ratio at the final $\mathrm{pH}$ of 8.5 by co-precipitation method.

Table 1. Composition ratio of the absorbents.

\begin{tabular}{cc}
\hline Sample No. & Composition Ratio of Ce:Fe:Mg \\
\hline 1 & $0.1: 0.1: 0.2$ \\
2 & $0.1: 0.1: 0.4$ \\
3 & $0.1: 0.1: 0.8$ \\
4 & $0.05: 0.1: 0.4$ \\
5 & $0.08: 0.1: 0.4$ \\
6 & $0.10: 0.1: 0.4$ \\
7 & $0.12: 0.1: 0.4$ \\
8 & $0.10: 0.05: 0.4$ \\
9 & $0.10: 0.1: 0.4$ \\
10 & $0.10: 0.15: 0.4$ \\
\hline
\end{tabular}

To obtain the suitable final $\mathrm{pH}$, three solutions all with a $\mathrm{Mg}$ :Fe:Ce molar concentration ratio of $4: 1: 1$ were prepared. Then the final $\mathrm{pH}$ of the three solution was adjusted by $6 \mathrm{~mol} \cdot \mathrm{L}^{-1} \mathrm{NaOH}$ to $8.5,9.0$, and 9.5, respectively. After that the solutions with various $\mathrm{pHs}$ were used to synthetize the adsorbents by the co-precipitation method.

To determine the best calcination temperature, the solution with a $\mathrm{Mg}: \mathrm{Fe}: \mathrm{Ce}$ molar concentration ratio of 4:1:1 was prepared. The final $\mathrm{pH}$ of the solution was adjusted by $6 \mathrm{~mol} \cdot \mathrm{L}^{-1} \mathrm{NaOH}$ to 8.5 . Then the solution was used to synthetize the adsorbent by the co-precipitation method. After that, the adsorbents were calcined in the muffle furnace at various temperatures for $3 \mathrm{~h}$, such as $100{ }^{\circ} \mathrm{C}, 200^{\circ} \mathrm{C}, 300^{\circ} \mathrm{C}, 400^{\circ} \mathrm{C}, 450{ }^{\circ} \mathrm{C}, 500{ }^{\circ} \mathrm{C}, 600{ }^{\circ} \mathrm{C}$, $700{ }^{\circ} \mathrm{C}$, and $800{ }^{\circ} \mathrm{C}$.

Finally, the adsorbents obtained were put into fluoride solutions with a $\mathrm{pH}$ of 7.0, and then they were all put into a constant temperature oscillation incubator with a temperature of $25{ }^{\circ} \mathrm{C}$ and an oscillation velocity of $120 \mathrm{rpm}$ for $24 \mathrm{~h}$. The solutions after adsorption were filtered by cellulose acetate membrane filters $(0.45 \mu \mathrm{m})$ and the $\mathrm{F}^{-}$concentrations were measured for the adsorption capacity.

\subsubsection{Fluoride Adsorption Experiments}

$\mathrm{pH}$ Influence Experiments

Firstly, a $100 \mathrm{~mL}$ solution with an $\mathrm{F}^{-}$concentration of $10 \mathrm{mg} \cdot \mathrm{L}^{-1}$ and a $100 \mathrm{~mL}$ solution with an $\mathrm{F}^{-}$concentration of $50 \mathrm{mg} \cdot \mathrm{L}^{-1}$ were prepared. Secondly, two adsorbent samples each with a weight of $15 \mathrm{mg}$ were added to the two solutions to obtained two absorbent doses of $150 \mathrm{mg} \cdot \mathrm{L}^{-1}$. The $\mathrm{pH}$ was then adjusted within the range of $3.0-10.0$ by $0.1 \mathrm{~mol} \cdot \mathrm{L}^{-1}$ hydrochloric acid and $0.1 \mathrm{~mol} \cdot \mathrm{L}^{-1}$ sodium hydroxide. Finally, all the solutions were placed into a constant temperature oscillation incubator with a rotation of $120 \mathrm{rpm}$ at $25^{\circ} \mathrm{C}$ for $24 \mathrm{~h}$.

\section{Adsorption Kinetics Experiments}

$\mathrm{NaF}$ was dissolved in distilled water to prepare an $\mathrm{F}^{-}$stock solution with an $\mathrm{F}^{-}$ concentration of $1000 \mathrm{mg} \cdot \mathrm{L}^{-1}$. The $\mathrm{F}^{-}$concentrations of $10 \mathrm{mg} \cdot \mathrm{L}^{-1}$ and $50 \mathrm{mg} \cdot \mathrm{L}^{-1}$ were prepared by diluting the solution with an $\mathrm{F}^{-}$concentration of $1000 \mathrm{mg} \cdot \mathrm{L}^{-1}$. The obtained MFC adsorbent was added to the two solutions to maintain the absorbent dose 
of $150 \mathrm{mg} \cdot \mathrm{L}^{-1}$. The $\mathrm{pH}$ was then adjusted to $7.0 \pm 0.2$, and the samples were collected at different time intervals for $24 \mathrm{~h}$.

Adsorption Isotherm Experiment

$\mathrm{NaF}$ was dissolved in distilled water to prepare several solutions, with initial $\mathrm{F}^{-}$ concentration of 2 to $40 \mathrm{mg} \cdot \mathrm{L}^{-1}$. The obtained MFC adsorbent was added to each test solution to maintain the absorbent dose of $150 \mathrm{mg} \cdot \mathrm{L}^{-1}$. The $\mathrm{pH}$ was then adjusted to $7.0 \pm 0.2$. Finally, they were shaken at a rotation of $120 \mathrm{rpm}$ and kept at $25^{\circ} \mathrm{C}$ for $24 \mathrm{~h}$.

Anionic Influence Experiments

Anionic solutions with initial $\mathrm{Cl}^{-}$and $\mathrm{SO}_{4}{ }^{2-}$ concentrations of $10-250 \mathrm{mg} \cdot \mathrm{L}^{-1}$, initial $\mathrm{NO}_{3}{ }^{-}$concentrations of $5-100 \mathrm{mg} \cdot \mathrm{L}^{-1}$, and initial $\mathrm{PO}_{4}{ }^{3-}$ concentrations of $1-50 \mathrm{mg} \cdot \mathrm{L}^{-1}$ were prepared. $\mathrm{NaF}$ was dissolved in each solution to maintain the initial $\mathrm{F}^{-}$concentration of $10 \mathrm{mg} \cdot \mathrm{L}^{-1}$. The MFC adsorbents were added to fix the MFC adsorbent dose of $150 \mathrm{mg} \cdot \mathrm{L}^{-1}$. The $\mathrm{pH}$ of each sample was then adjusted to $7.0 \pm 0.2$. They were then placed in a constant temperature oscillation incubator, shaken at $120 \mathrm{rpm}$, and kept at $25^{\circ} \mathrm{C}$ for $24 \mathrm{~h}$.

\subsubsection{Surface Properties Tests}

The surface properties of an adsorbent are the decisive factors that affect the adsorption properties. To further analyze the adsorption mechanism of the prepared adsorbent, the surface properties of the adsorbent were tested. The XRD method was used for the crystalline structure of the adsorbents through an X-ray powder diffractometer with a $\mathrm{Cu} \mathrm{K} \alpha$ source under a scanning rate of $4^{\circ} \cdot \mathrm{min}^{-1}$ in the $2 \theta$ ranging from $10^{\circ}$ to $70^{\circ}$ and operated at $40 \mathrm{kV}$ and $100 \mathrm{~mA}$. An FTIR spectrometer was applied for FTIR analysis of the adsorbent.

\subsubsection{Calculation of Equilibrium Adsorption Capacity}

The equilibrium adsorption capacity of the adsorbent is an important indicator that affects the performance of the adsorbent. It can be expressed as follows. [25]

$$
Q_{e}=\frac{\left(C_{0}-C_{e}\right) V_{0}}{m}
$$

where $Q_{e}$ is the equilibrium adsorption capacity of the adsorbent $\left(\mathrm{mg} \cdot \mathrm{g}^{-1}\right) ; C_{0}$ and $C_{e}$ are the initial and final $\mathrm{F}^{-}$concentrations $\left(\mathrm{mg} \cdot \mathrm{L}^{-1}\right)$, respectively; $V_{0}$ is the volume of the solution $(\mathrm{L})$; and $\mathrm{m}$ is the mass of the adsorbents $(\mathrm{g})$.

\section{Results}

\subsection{Optimization of the Adsorbent}

The obtained results from the experiments for optimizing the metal composition, the preparation methods, the proper $\mathrm{pH}$, and the calcination temperature of the adsorbent are shown in Figure 2a-d. In general, under the various initial $\mathrm{F}^{-}$concentrations from $0-40 \mathrm{mg} \cdot \mathrm{L}^{-1}$, the equilibrium adsorption capacity of the three metal compositions is shown as an order of Mg-Fe-Ce $>\mathrm{Zn}-\mathrm{Al}-\mathrm{Ce}>\mathrm{Zn}$-Fe-Ce. Meanwhile, the adsorbents with MFC metal components exhibited significant advantages in equilibrium adsorption capacity under various initial $\mathrm{F}^{-}$concentrations compared with the $\mathrm{Zn}$-Fe-Ce adsorbent and $\mathrm{Zn}$-Fe$\mathrm{Ce}$ adsorbent. Therefore, $\mathrm{Mg}$, Fe, and Ce were selected as the optimal metal components of the adsorbent. 

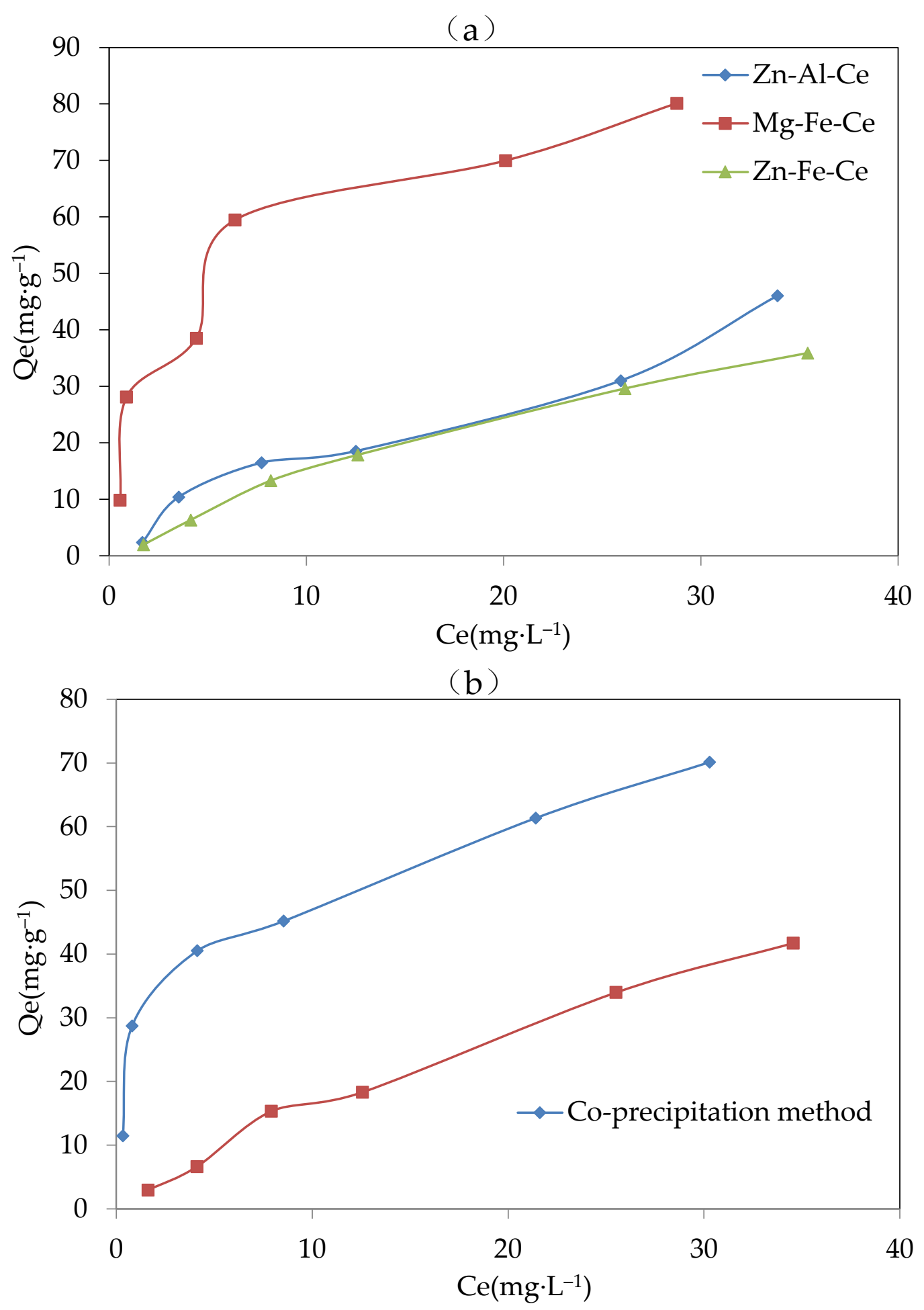

Figure 2. Cont. 

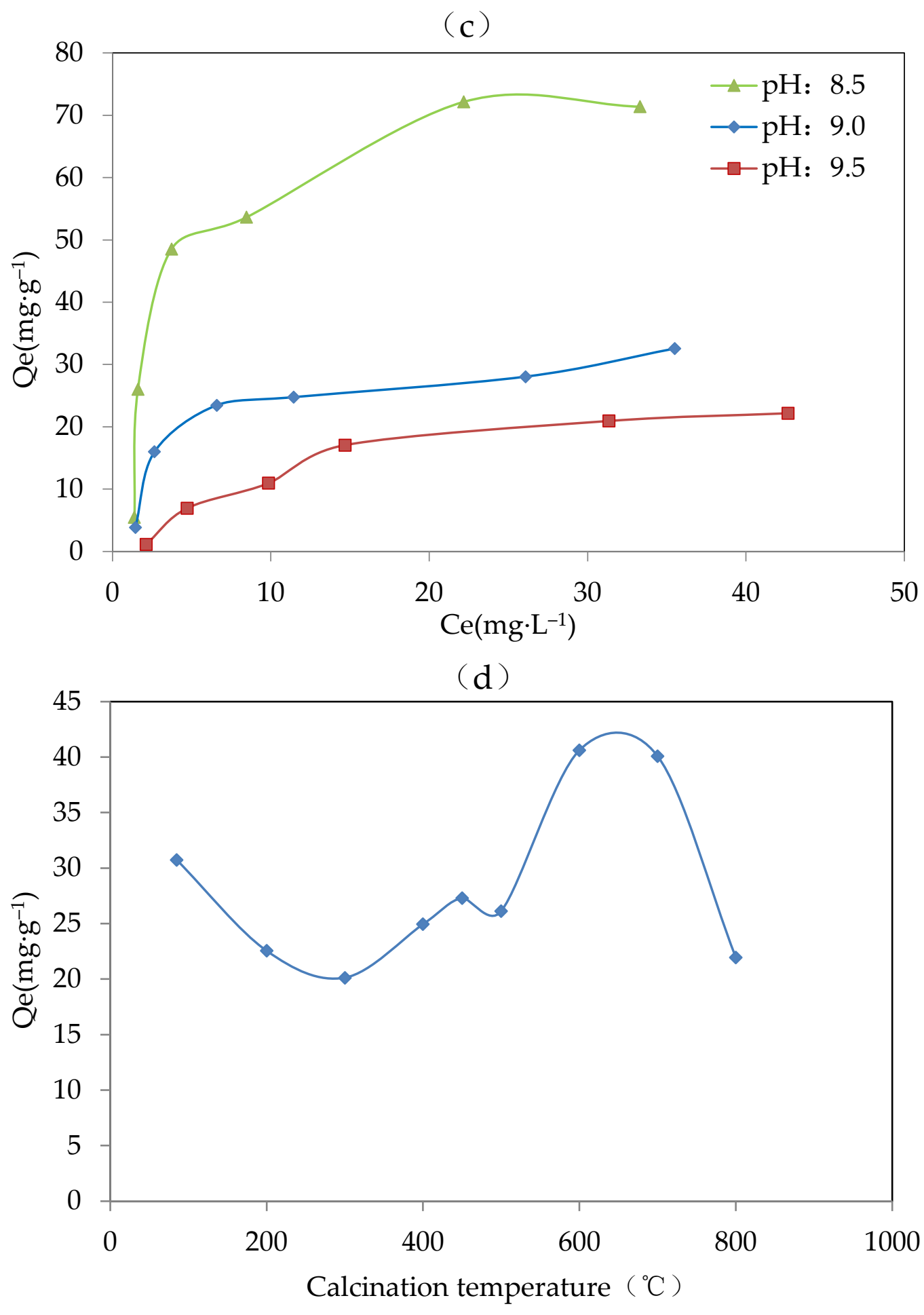

Figure 2. Results of the adsorbent optimization for (a) metal components ( $\mathrm{pH}, 8.5$; method, co-precipitation; and calcination temperature, $600{ }^{\circ} \mathrm{C}$ ), (b) preparation methods (adsorbent, $\mathrm{Mg}$-Fe-Ce; $\mathrm{pH}, 7$; and temperature, $600{ }^{\circ} \mathrm{C}$ ), (c) proper $\mathrm{pH}$ (adsorbent, $\mathrm{Mg}-\mathrm{Fe}-\mathrm{Ce}$; method, co-precipitation; and calcination temperature, $600{ }^{\circ} \mathrm{C}$ ), and (d) calcination temperature (adsorbent, Mg-Fe-Ce; pH, 7; and method, co-precipitation).

Compared with the adsorbent prepared by the hydrothermal synthesis method, the adsorbent prepared by the co-precipitation method had obvious advantages in the equilibrium adsorption capacity. The equilibrium adsorption capacity of the adsorbent made by the co-precipitation method was twice that of the adsorbent made by the hydrothermal 
synthesis method. This might be because the mixed solution for the adsorbent was stirred completely in the co-precipitation method, unlike in the hydrothermal method. The adsorbent prepared by the co-precipitation method could possess more adsorption sites and a stronger adsorption capacity. Therefore, the co-precipitation method was chosen as the adsorbent preparation measure.

The equilibrium adsorption capacity under a $\mathrm{pH}$ value of 8.5 was significantly greater than that with a $\mathrm{pH}$ value of 9.0 and 9.5. This might be because there was more hydroxyl ion in the solution with the higher final $\mathrm{pH}$. The environment with a higher concentration of hydroxyl ion could promote the complete precipitation process, which was unfavorable for the existence of various valence states of the same metal ion. However, the existence of various valence states of the same metal ion was helpful for fluoride adsorption. Therefore, the low adsorption activity of the adsorbent was exhibited at a $\mathrm{pH}$ above 8.5. Finally, the appropriate $\mathrm{pH}$ value for preparing the adsorbent was set to 8.5.

The calcination temperature could destroy the amorphous structure, and thereby affect the $\mathrm{F}^{-}$removal effect. From Figure $2 \mathrm{~d}$, it was indicated that when the calcination temperature was $600^{\circ} \mathrm{C}$, the value of the equilibrium adsorption capacity was the highest at about $40.62 \mathrm{mg} \cdot \mathrm{g}^{-1}$. The results showed that the adsorbent produced at $600{ }^{\circ} \mathrm{C}$ had better adsorption capacity. Therefore, $600{ }^{\circ} \mathrm{C}$ was chosen as the optimal calcination temperature.

In addition, the equilibrium adsorption capacity $(\mathrm{Qe})$ of adsorbents with different composition ratios were compared. It was found that the adsorbent with a $\mathrm{Mg}: \mathrm{Fe}: \mathrm{Ce}$ composition ratio of 4:1:1 can possess a higher Qe value. For example, three solutions with Mg:Fe:Ce molar concentrations of 0.4:0.1:0.08, 0.2:0.1:0.10, and 0.8:0.1:0.12 were prepared and the corresponding adsorbents were synthesized by the co-precipitation method. When the adsorption experiments were carried out, the adsorbent with a Mg:Fe:Ce composition ratio of 0.4:0.1:0.10 exhibited a higher Qe value $\left(6.79 \mathrm{mg} \cdot \mathrm{g}^{-1}\right)$ than that of the $\mathrm{Mg}: \mathrm{Fe}: \mathrm{Ce}$ composition ratios of 0.4:0.1:0.08 (3.43 $\left.\mathrm{mg} \cdot \mathrm{g}^{-1}\right)$ and 0.4:0.1:0.12 $\left(2.80 \mathrm{mg} \cdot \mathrm{g}^{-1}\right)$. Therefore, 4:1:1 was chosen as the optimal the composition ratio of $\mathrm{Mg}: \mathrm{Fe}: \mathrm{Ce}$.

Given that all the optimal parameters (i.e., metal composition, preparation method, composition ratio, final $\mathrm{pH}$, and calcination temperature) for the preparation of the adsorbent were obtained, the MFC adsorbent was prepared. The detailed preparation processes was as follows. Firstly, $20.3 \mathrm{~g} \mathrm{MgCl}_{2} \cdot 6 \mathrm{H}_{2} \mathrm{O}, 6.95 \mathrm{~g} \mathrm{FeSO}_{4} \cdot 7 \mathrm{H}_{2} \mathrm{O}$, and $10.10 \mathrm{~g} \mathrm{Ce}\left(\mathrm{SO}_{4}\right)_{2} \cdot 4 \mathrm{H}_{2} \mathrm{O}$ were dissolved in $250 \mathrm{~mL}$ deionized water. Then they were stirred with a magnetic stirrer until completely dissolved to obtain an initial mixed solution for the absorbent. It took about $30 \mathrm{~min}$. Then, the $\mathrm{NaOH}$ solution with a molar concentration of $6 \mathrm{~mol} \cdot \mathrm{L}^{-1}$ was used to adjust the final solution $\mathrm{pH}$ of 8.5 and the final $\mathrm{pH}$ lasted more than $30 \mathrm{~min}$. After that, the solution was left for $24 \mathrm{~h}$ at room temperature in order to obtain the precipitate completely. The precipitate was then washed several times with distilled water and centrifuged. The residue after centrifugation was dried in an oven at a temperature of $65^{\circ} \mathrm{C}$ for $24 \mathrm{~h}$ and then ground to MFC adsorbent power. The MFC adsorbent power was calcined at $600{ }^{\circ} \mathrm{C}$ in a muffle furnace for $3 \mathrm{~h}$.

\subsection{Effects of Solution $p H$}

For $\mathrm{F}^{-}$adsorption, $\mathrm{pH}$ is considered to be one of the key factors that determines the adsorption performance of the adsorbent. To investigate the influence of $\mathrm{pH}$ on the adsorption performance of MFC adsorbents, two initial $\mathrm{F}^{-}$concentrations $\left(10 \mathrm{mg} \cdot \mathrm{L}^{-1}\right.$ and $50 \mathrm{mg} \cdot \mathrm{L}^{-1}$ ) were designed under a $\mathrm{pH}$ range of 3-10. As shown in Figure 3, the results indicated that under various $\mathrm{pH}$ values, the equilibrium adsorption capacity of the solution usually decreased as the $\mathrm{pH}$ value increased, and the equilibrium adsorption capacity under $50 \mathrm{mg} \cdot \mathrm{L}^{-1}$ was higher than that under $10 \mathrm{mg} \cdot \mathrm{L}^{-1}$. In addition, for the solution with an initial $\mathrm{F}^{-}$concentration of $10 \mathrm{mg} \cdot \mathrm{L}^{-1}$, the maximum equilibrium adsorption capacity $\left(65 \mathrm{mg} \cdot \mathrm{g}^{-1}\right.$ ) could be obtained at $\mathrm{pH} 4-5.5$, which was chosen as the optimal $\mathrm{pH}$. For the solution with an initial $\mathrm{F}^{-}$concentration of $50 \mathrm{mg} \cdot \mathrm{L}^{-1}$, the maximum equilibrium adsorption capacity $\left(152 \mathrm{mg} \cdot \mathrm{g}^{-1}\right)$ was obtained at a $\mathrm{pH}$ below 3.0. The optimal $\mathrm{pH}$ tended to be acidic. However, higher adsorption performances also happened under neutral 
$\mathrm{pH}$ conditions. The results were similar to the results of $\mathrm{Xu}$ et al. (2001) and Zhou et al. (2004) [39,42].

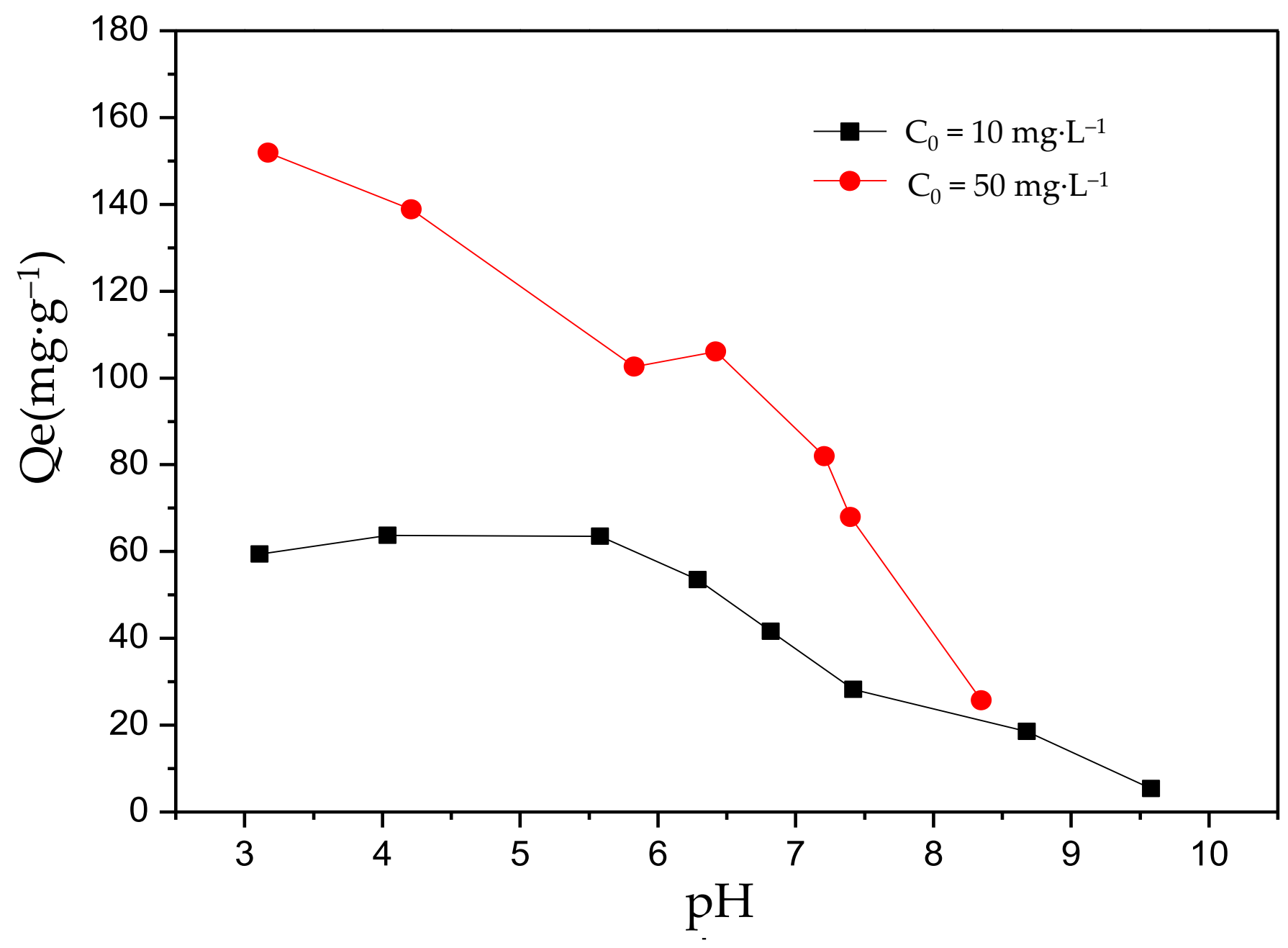

Figure 3. The effect of $\mathrm{pH}$ on the adsorption of fluorine by the MFC adsorbent.

From this point, as the $\mathrm{pH}$ value increased, the free hydroxide ions increased and could be combined with the active sites on the absorbent, occupying these sites, and hindering the combinations between $\mathrm{F}^{-}$and the active sites, which directly resulted in a decrease in the $\mathrm{F}^{-}$absorption amount. Meanwhile, $\mathrm{pH}$ value affected the charge on the surface of the adsorbent. There were two possible situations: (1) As the $\mathrm{pH}$ value increased, the positive charge on the surface of the absorbent became negative, or (2) the positive charge on the surface of the absorbent increased as the $\mathrm{pH}$ value decreased. Both of these weakened the electrostatic adsorption and cause a decrease in the adsorption capacity. In addition, the absorbent maintained a high absorption level in the neutral environment. For example, when the initial $\mathrm{F}^{-}$concentrations were $10 \mathrm{mg} \cdot \mathrm{L}^{-1}$ and $50 \mathrm{mg} \cdot \mathrm{L}^{-1}$, the absorption amounts were $35 \mathrm{mg} \cdot \mathrm{g}^{-1}$ and $90 \mathrm{mg} \cdot \mathrm{g}^{-1}$, respectively. This indicated that the novel MFC adsorbent can be used to remove $\mathrm{F}^{-}$from high fluoride water.

\subsection{Kinetic Study}

Figure 4 shows the kinetic curves of $\mathrm{F}^{-}$adsorption under different initial $\mathrm{F}^{-}$concentrations. The adsorption capacity under different scenarios had the same trend of variation, and the adsorption rates were fast in the first $240 \mathrm{~min}$. For example, when the initial $\mathrm{F}^{-}$ concentrations were $10 \mathrm{mg} \cdot \mathrm{L}^{-1}$ and $50 \mathrm{mg} \cdot \mathrm{L}^{-1}$, the adsorption capacity under the first $240 \mathrm{~min}$ accounted for $83 \%$ and $95 \%$ of the equilibrium adsorption capacity of the solution, 
respectively. The maximum $\mathrm{F}^{-}$adsorption capacities were $40 \mathrm{mg} \cdot \mathrm{g}^{-1}$ and $75 \mathrm{mg} \cdot \mathrm{g}^{-1}$ for the initial $\mathrm{F}^{-}$concentrations of $10 \mathrm{mg} \cdot \mathrm{L}^{-1}$ and $50 \mathrm{mg} \cdot \mathrm{L}^{-1}$, respectively, and remained unchanged for $720 \mathrm{~min}\left(12 \mathrm{~h}\right.$ ). This may be because the $\mathrm{F}^{-}$concentrations were at a higher level at the beginning of the $\mathrm{F}^{-}$absorption process, and more active adsorption sites on the adsorbent worked than other processes. In the first $240 \mathrm{~min}$, the adsorption driving force was large, and that drove a rapid adsorption process. In addition, part of the $\mathrm{F}^{-}$was adsorbed by the adsorbents and the $\mathrm{F}^{-}$concentrations decreased during the adsorption process. At the same time, the number of active adsorption sites was reduced due to the binding of $\mathrm{F}^{-}$. The reduction in the driving force resulted in a reduction in the adsorption rate for $720 \mathrm{~min}$. Due to the balance of $\mathrm{F}^{-}$desorption and adsorption, the adsorption rate remained unchanged, and the adsorption capacity reached the highest value after $720 \mathrm{~min}$.

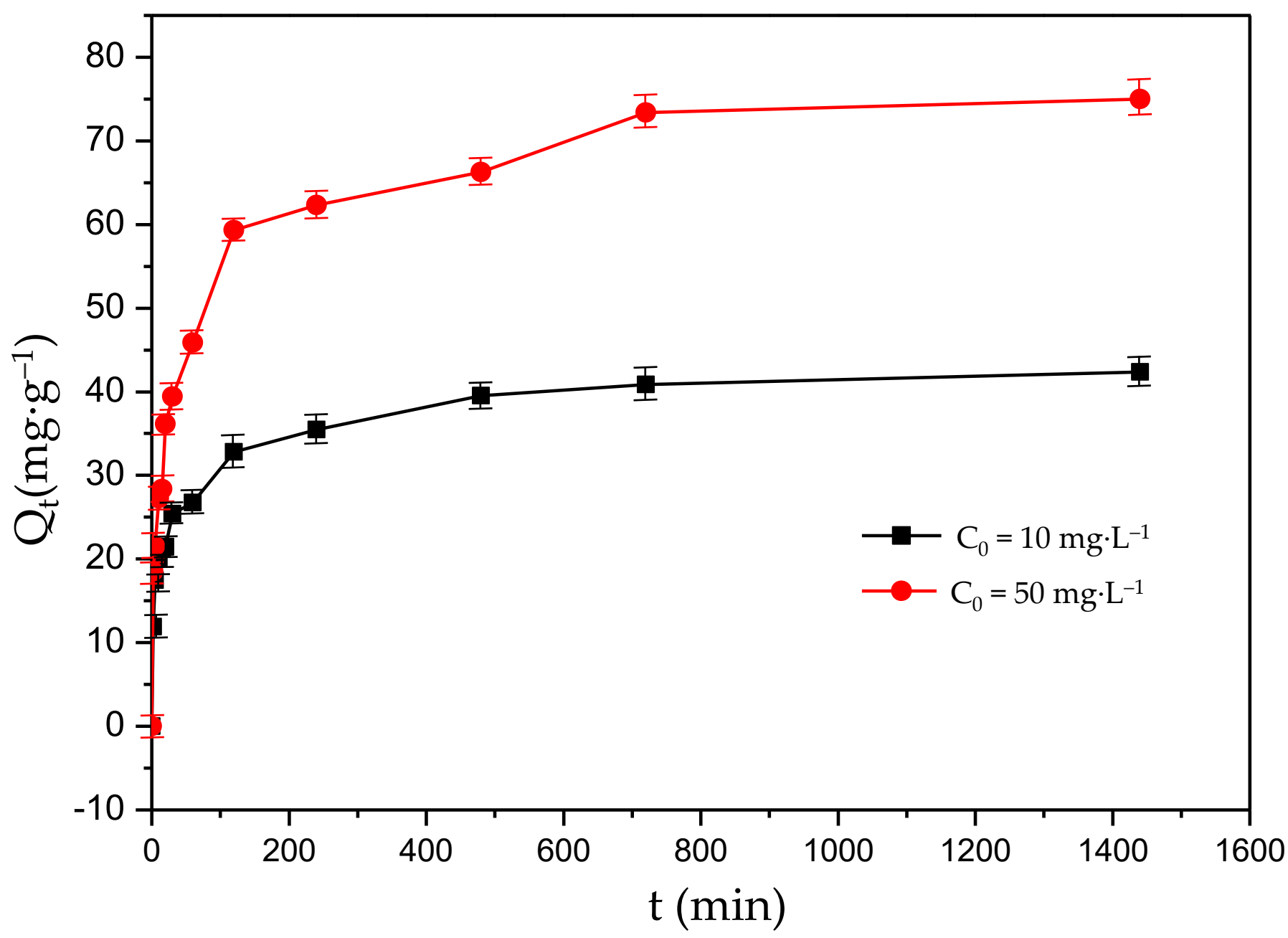

Figure 4. Kinetic curves of fluoride adsorption on the MFC adsorbent.

The pseudo-first-order rate model and pseudo-second-order rate model were applied to fit the kinetic data. They can be described as follows [17,43].

$$
\begin{gathered}
\log \left(Q_{e}-Q_{t}\right)=\log Q_{e}-k_{1} t / 2.303 \\
\frac{t}{Q_{t}}=\frac{1}{k_{2} Q_{e}^{2}}+\frac{1}{Q_{e}} t
\end{gathered}
$$

where $Q_{e}\left(\mathrm{mg} \cdot \mathrm{g}^{-1}\right)$ and $Q_{t}\left(\mathrm{mg} \cdot \mathrm{g}^{-1}\right)$ denote the $\mathrm{F}^{-}$adsorption capacities at equilibrium and at any time (t), respectively; and $k_{1}$ and $k_{2}$ denote the rate constants of the pseudofirst-order and pseudo-second-order adsorption reaction, respectively. Compared with 
the experimental and theoretical values of $Q_{e}$ and $\mathrm{R}^{2}$ of the kinetic curves for the pseudofirst-order rate model and pseudo-second-order model in different $\mathrm{F}^{-}$concentrations, the pseudo-second-order model fit best. The $\mathrm{R}^{2}$ value of the pseudo-first-order rate model and pseudo-second-order rate model were 0.9588 and 0.9989 , respectively, for $10 \mathrm{mg} \cdot \mathrm{L}^{-1}$, and 0.9482 and 0.9979 , respectively, for $50 \mathrm{mg} \cdot \mathrm{L}^{-1}$. The best fit for the pseudo-second-order model was obtained (as shown in Figure 5), and indicated that the adsorption process might be chemisorption. The achieved rate constants $\left(k_{2}\right)$ of kinetic study for $10 \mathrm{mg} \cdot \mathrm{L}^{-1}$ and $50 \mathrm{mg} \cdot \mathrm{L}^{-1}$ were $10.3 \times 10^{-4} \mathrm{~g} \cdot(\mathrm{mg} \cdot \mathrm{min})^{-1}$ and $5.5 \times 10^{-4} \mathrm{~g} \cdot(\mathrm{mg} \cdot \mathrm{min})^{-1}$, respectively. A larger rate constant means a faster adsorption process. This indicates that the adsorption process under the lower initial $\mathrm{F}^{-}$concentration $\left(10 \mathrm{mg} \cdot \mathrm{L}^{-1}\right)$ was faster than that under the higher initial $\mathrm{F}^{-}$concentration $\left(50 \mathrm{mg} \cdot \mathrm{L}^{-1}\right)$. The adsorption process of the MFC adsorbent may be mainly an inner-pore diffusion process.

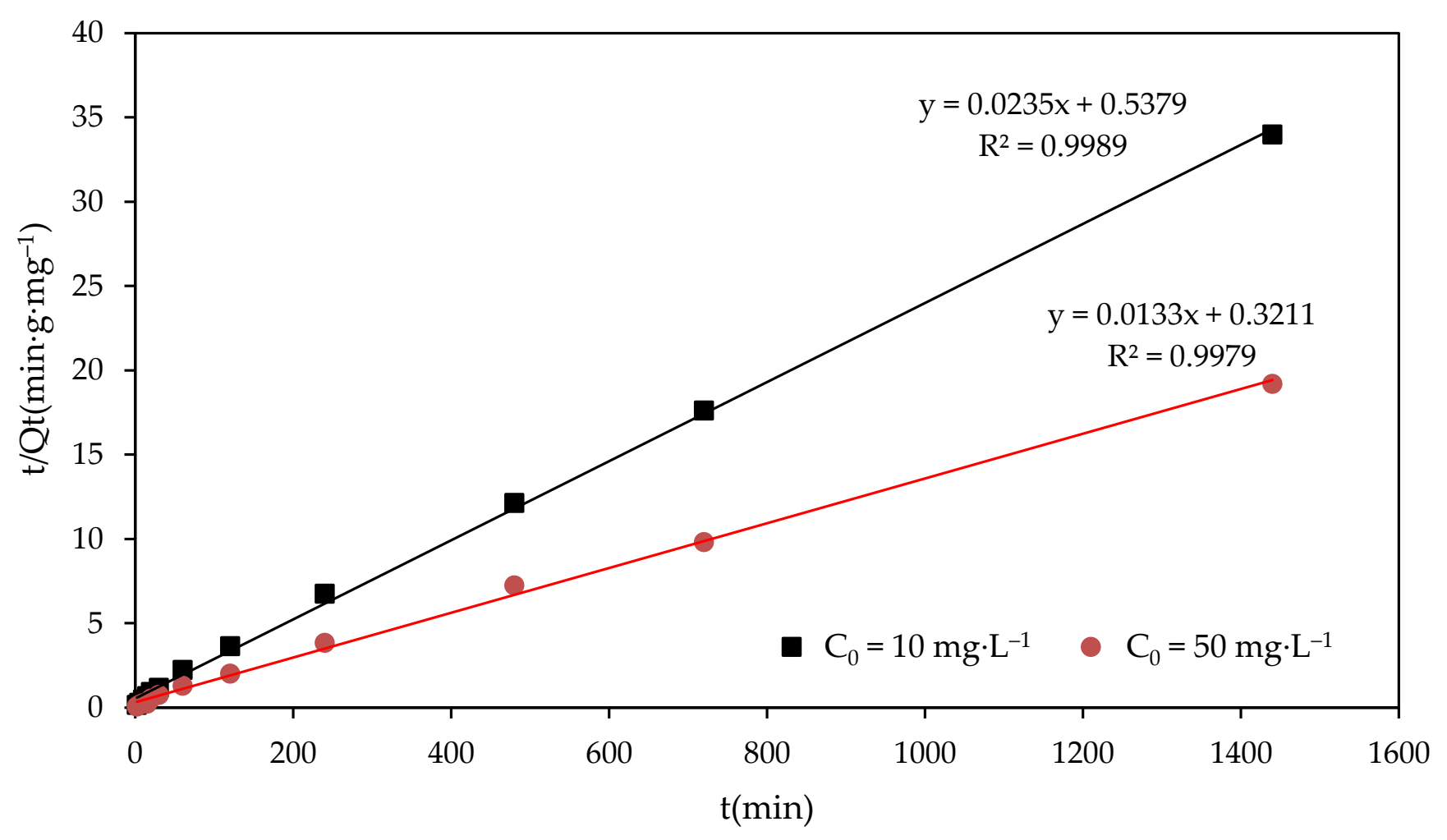

Figure 5. Kinetic curves for the pseudo-second-order model of fluoride adsorption on the MFC adsorbent.

\subsection{Adsorption Isotherm}

Langmuir isotherm models were applied to describe the relationship between the $\mathrm{F}^{-}$concentration and adsorption capacity at the adsorption equilibrium. There are two Langmuir isotherm models, a one-site Langmuir model and a two-site Langmuir model. The one-site Langmuir model is based on the following assumption: Only one type of adsorption site exists on the surface of the adsorbent. The energy of the adsorption sites is the same, and there is no interaction among the adsorbed molecules in the solution. It can be described as follows:

$$
Q_{e}=\frac{Q_{\max } b C_{e}}{1+b C_{e}}
$$

where $Q_{e}\left(\mathrm{mg} \cdot \mathrm{g}^{-1}\right)$ and $Q_{\max }\left(\mathrm{mg} \cdot \mathrm{g}^{-1}\right)$ represent the equilibrium and maximum adsorption capacity, respectively; $C_{e}\left(\mathrm{mg} \cdot \mathrm{L}^{-1}\right)$ represents the equilibrium concentration in solution; and $\mathrm{b}\left(\mathrm{L} \cdot \mathrm{mg}^{-1}\right)$ represents the Langmuir constant related to the adsorption-desorption affinity. The two-site Langmuir model is based on the following assumption: There are 
two types of adsorption sites, one with higher affinity and other with lower affinity. It can be described as the following Equation (5):

$$
Q_{e}=\frac{Q_{1} b_{1} C_{e}}{1+b_{1} C_{e}}+\frac{Q_{2} b_{2} C_{e}}{1+b_{2} C_{e}}
$$

where $Q_{e}\left(\mathrm{mg} \cdot \mathrm{g}^{-1}\right), Q_{1}\left(\mathrm{mg} \cdot \mathrm{g}^{-1}\right)$, and $Q_{2}\left(\mathrm{mg} \cdot \mathrm{g}^{-1}\right)$ represent the equilibrium adsorption capacity, maximum adsorption capacity at higher affinity sites, and maximum adsorption capacity at lower affinity sites, respectively; $C_{e}\left(\mathrm{mg} \cdot \mathrm{L}^{-1}\right)$ represents the equilibrium concentration in solution; and $b_{1}\left(\mathrm{~L} \cdot \mathrm{mg}^{-1}\right)$ and $b_{1}\left(\mathrm{~L} \cdot \mathrm{mg}^{-1}\right)$ represent the Langmuir constant related to the higher affinity and lower affinity sites, respectively.

The sorption isotherm of $\mathrm{F}^{-}$on the $\mathrm{Mg}$-Fe-Ce adsorbent with temperature $(\mathrm{T})=25^{\circ} \mathrm{C}$ and $\mathrm{pH}=7.0 \pm 0.2$ is shown in Figure 6. The corresponding parameters of the one-site and two-site Langmuir isotherm models are listed in Table 2, where Q1 and Q2 can be obtained from the calculation of the soft origin of 9.1. It was found that the experimental data were fitted not only by the one-site Langmuir isotherm model but also by the two-site Langmuir isotherm model. The correlation coefficient $\left(R^{2}\right)$ of both models was greater than 0.94 . However, the two-site Langmuir isotherm model gave a more satisfactory fitting result $\left(R^{2}=0.96\right)$ than the one-site Langmuir isotherm model $\left(R^{2}=0.94\right)$. The results showed that there may be two adsorption sites with different affinities on the surface of the MFC adsorbent. Although higher affinity sites are more likely to be occupied by $\mathrm{F}^{-}$than lower affinity sites $\left(b_{1} / b_{2}=52\right)$, a lower $Q_{1} / Q_{\max }$ value $(30.9 \%)$ was obtained from Table 2 . It was found that the adsorption capacity of lower energy sites was higher than the adsorption capacity of higher energy sites. This indicated that the active sites may be mainly sites with lower energy sites, and fewer sites with higher energy [44]. In the beginning of the adsorption, $\mathrm{F}^{-}$was adsorbed in higher affinity sites, and the adsorption rate was fast, lasting for several minutes with little absorption (as shown in Figure 4). In addition, the experimental data showed that when the equilibrium concentration was $27 \mathrm{mg} \cdot \mathrm{L}^{-1}$, the adsorption capacity of $\mathrm{F}^{-}$was $80 \mathrm{mg} \cdot \mathrm{g}^{-1}$. Moreover, the theoretical maximum adsorption capacity $\left(Q_{\max }\right)$ was calculated as $85 \mathrm{mg} \cdot \mathrm{g}^{-1}$ and $204 \mathrm{mg} \cdot \mathrm{g}^{-1}$ by one-site and two-site Langmuir models, respectively. Compared with the $\mathrm{F}^{-}$sorption capacities of various sorbents in Table 3, the materials in this study were highly competitive compared to other products.

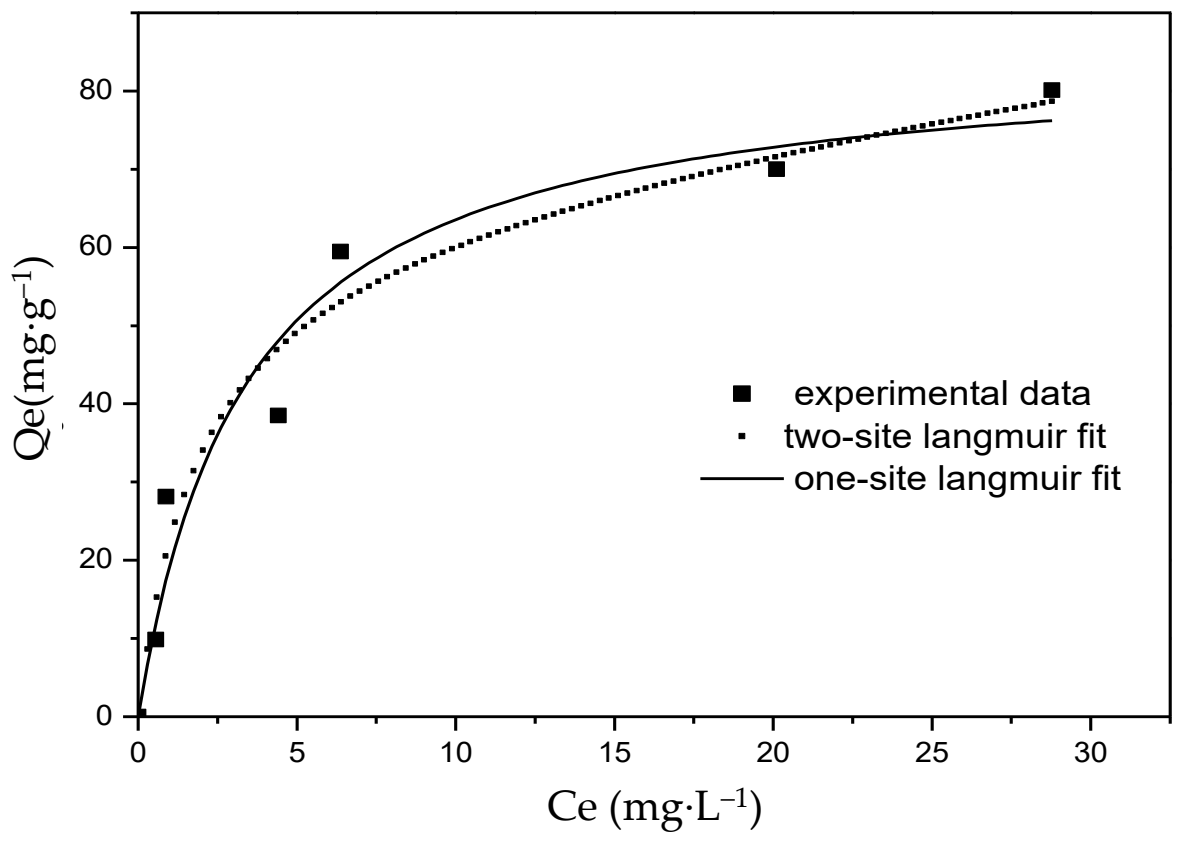

Figure 6. Fluoride adsorption isotherm at $\mathrm{pH}=7.0 \pm 0.2$. 
Table 2. Comparison of one-site and two-site Langmuir isotherm parameters of fluoride adsorbed from the Mg-FeCe absorbent.

\begin{tabular}{cccccccc}
\hline \multicolumn{3}{c}{ One-Site Langmuir } & \multicolumn{5}{c}{ Two-Site Langmuir } \\
\hline $\begin{array}{c}Q_{\max } \\
\left(\mathrm{mg} \cdot \mathrm{g}^{-1}\right)\end{array}$ & $\begin{array}{c}b \\
\left(\mathrm{~L} \cdot \mathrm{mg}^{-1}\right)\end{array}$ & $R^{2}$ & $\begin{array}{c}Q_{1} \\
\left(\mathrm{mg} \cdot \mathrm{g}^{-1}\right)\end{array}$ & $\begin{array}{c}Q_{2} \\
\left(\mathrm{mg}^{-1} \mathrm{~g}^{-1}\right)\end{array}$ & $\begin{array}{c}Q_{\max }=Q_{1} \\
+Q_{2} \\
\left(\mathrm{mg} \cdot \mathrm{g}^{-1}\right)\end{array}$ & $\begin{array}{c}b_{1} \\
\left(\mathrm{~L} \cdot \mathrm{mg}^{-1}\right)\end{array}$ & $\begin{array}{c}b_{2} \\
\left(\mathrm{~L} \cdot \mathrm{mg}^{-1}\right)\end{array}$ \\
\hline 85 & 0.29 & 0.94 & 63 & 141 & 204 & 0.52 & 0.01 \\
\hline
\end{tabular}

Table 3. Comparison of fluoride adsorption capacity of the MFC adsorbent with other adsorbents.

\begin{tabular}{cccc}
\hline Adsorbents & $\mathbf{p H}$ & $Q_{e}\left(\mathbf{m g} \cdot \mathbf{g}^{-\mathbf{1}}\right)$ & References \\
\hline Fe-Al-Ce composite & 7.0 & 178 & {$[29]$} \\
$\mathrm{La}^{3+}$-exchanged zeolite F-9 & 7.2 & 54.28 & {$[44]$} \\
$\mathrm{Al}^{3+}$-exchanged zeolite F-9 & $5.2-5.3$ & 39.52 & {$[44]$} \\
Mg-Fe-Ce composite & 7.0 & 204 & Present study \\
\hline
\end{tabular}

\subsection{Effects of Coexisting Anions}

The presence of anions may be competitive for the absorption of $\mathrm{F}^{-}$. Sulfate $\left(\mathrm{SO}_{4}{ }^{2-}\right)$, nitrate $\left(\mathrm{NO}_{3}{ }^{-}\right)$, chloride $\left(\mathrm{Cl}^{-}\right)$, and phosphate $\left(\mathrm{PO}_{4}{ }^{3-}\right)$ are the common anions in groundwater composition. The effects of coexisting anions such as $\mathrm{SO}_{4}{ }^{2-}, \mathrm{NO}_{3}{ }^{-}, \mathrm{Cl}^{-}$, and $\mathrm{PO}_{4}{ }^{3-}$ were thereby examined. The results are given in Figure 7. It shows that even at a concentration of $100 \mathrm{mg} \cdot \mathrm{L}^{-1}$, nitrate ions do not significantly interfere with the removal of $\mathrm{F}^{-}$. $\mathrm{SO}_{4}{ }^{2-}$ and $\mathrm{Cl}^{-}$exhibited a similar trend. The equilibrium adsorption capacity showed a small variety when the concentrations of $\mathrm{SO}_{4}{ }^{2-}$ and $\mathrm{Cl}^{-}$were at a range of $5-250 \mathrm{mg} \cdot \mathrm{L}^{-1}$. On the contrary, a significant variety in the equilibrium adsorption capacity of $\mathrm{F}^{-}$was exhibited when the concentrations of $\mathrm{PO}_{4}{ }^{3-}$ were in the range of $0-100 . \mathrm{SO}_{4}{ }^{2-}, \mathrm{NO}_{3}{ }^{-}$, and $\mathrm{Cl}^{-}$usually had a weak influence on $\mathrm{F}^{-}$adsorption and the influence of coexisting anion effects on $\mathrm{F}^{-}$was arranged in the descending order of $\mathrm{PO}_{4}{ }^{3-}>\mathrm{SO}_{4}{ }^{2-}>\mathrm{Cl}^{-}>\mathrm{NO}_{3}{ }^{-}$. The results were similar to Liu's study [45]. Additionally, $\mathrm{PO}_{4}{ }^{3-}$ showed strong competitive adsorption with $\mathrm{F}^{-}$. When the $\mathrm{PO}_{4}{ }^{3-}$ concentration increased from $1 \mathrm{mg} \cdot \mathrm{L}^{-1}$ to $10 \mathrm{mg} \cdot \mathrm{L}^{-1}$, the equilibrium adsorption capacity decreased by about $50 \%$, which indicated that $\mathrm{PO}_{4}{ }^{3-}$ had a strong inhibitory effect on the adsorption of $\mathrm{F}^{-}$. These results were also obtained in previous studies $[46,47]$. Therefore, more attention should be paid to the $\mathrm{PO}_{4}{ }^{3-}$ concentration in the practical engineering application of the novel $\mathrm{Mg}$-Fe-Ce adsorbent and measures should be taken for $\mathrm{PO}_{4}{ }^{3-}$ removal. Fortunately, $\mathrm{PO}_{4}{ }^{3-}$ concentrations in groundwater are normally low, and the effect on the $\mathrm{F}^{-}$sorption is limited [45]. Taking all the above factors into consideration, the adsorbent prepared in this study was engineering-favorable.
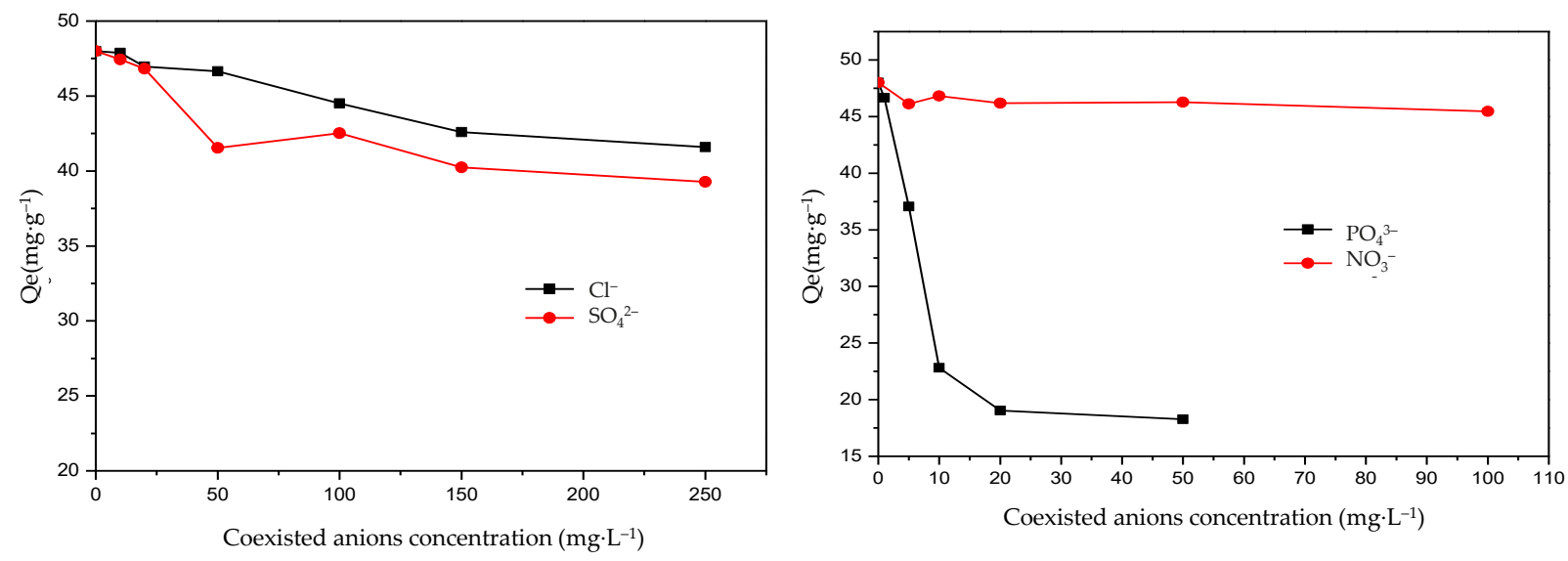

Figure 7. Effects on fluoride adsorption of coexisting anions (Qe: the equilibrium adsorption capacity of fluoride). 


\subsection{Surface Properties and Adsorption Mechanism Analysis}

\subsubsection{XRD Analysis}

Figure 8 shows the XRD patterns of the MFC adsorbent for its crystal structure. It was found that there existed no crystal diffraction peaks of MFC adsorbents, and the MFC adsorbents had an amorphous structure. According to crystal chemistry, when the structure of the adsorbents was in the transition from amorphous to crystal form, more surface free energy and a thermodynamically unstable state is acquired. Oxides with surface hydroxyl groups had higher activity. Moreover, the sorption capacity was related to the amorphous structure of the adsorbents, and the destruction of the amorphous structure of the adsorbents resulted in a decrease in the adsorption capacity for $\mathrm{F}^{-}$. Moreover, there was a large and wide peak packet from $20^{\circ}$ to $40^{\circ}$ at two theta angles. This can be attributed to the short-range order characterization of amorphous metal oxide.

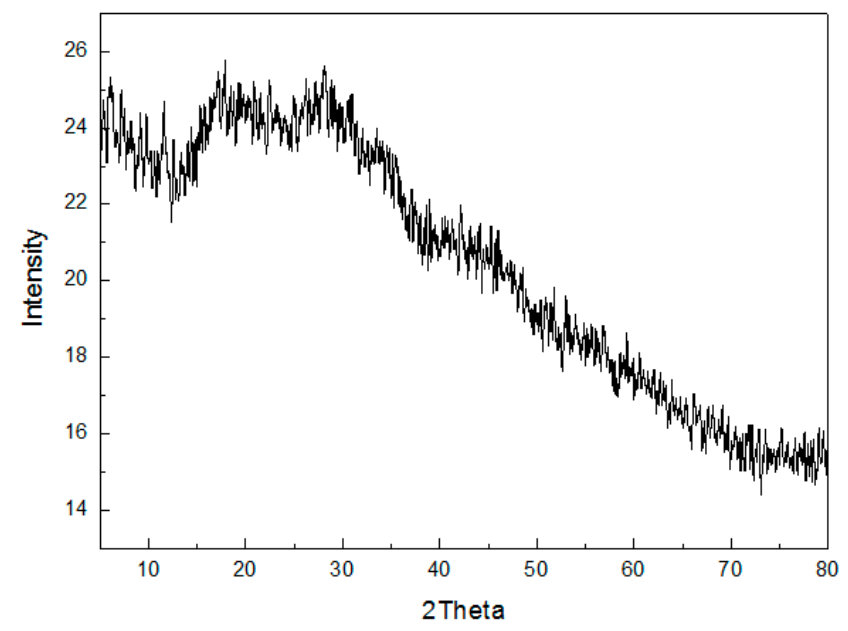

Figure 8. XRD patterns of the MFC adsorbents.

\subsubsection{FTIR Spectroscopy}

Figure 9 shows the FTIR spectra of MFC adsorbent samples before and after fluoride adsorption. The sample before fluoride adsorption was prepared from a solution with a final $\mathrm{pH}$ of 8.5 and synthesized by the co-precipitation method. The sample after fluoride adsorption was obtained after adsorption in the solution with a fluoride concentration of $400 \mathrm{mg} \cdot \mathrm{L}^{-1}$ and the $\mathrm{pH}$ was 7.0. The MFC adsorbent was a composite metal oxide adsorbent with hydroxyl groups on the surface. The stretching vibration of hydroxyl groups on the metal surface usually occurred below $1200 \mathrm{~cm}^{-1}$, and there was no bending vibration mode near $1600 \mathrm{~cm}^{-1}$. It was found that some peaks appeared between 1200 and $0 \mathrm{~cm}^{-1}$ in Figure 9. They were characterized as a stretching vibration of hydroxyl groups on the metal surface. There existed a broad band at $3400 \mathrm{~cm}^{-1}$ in the spectrum of the $\mathrm{Mg}$-Fe-Ce adsorbent. This can be attributed to the stretching vibration of adsorbed water. It indicated that the stretching vibration peak intensity of the hydroxyl groups on the adsorbent surface were significantly reduced at $1125 \mathrm{~cm}^{-1}$, and an exchange reaction might have occurred between $\mathrm{OH}$-and $\mathrm{F}^{-}$. This can be explained by the similar dimensions exhibited by $\mathrm{OH}^{-}$and $\mathrm{F}^{-}$. In addition, there were new peaks (marked with the orange line) in the spectrum of the MFC adsorbent after fluoride adsorption. This might be explained by the formed Mg-F, Fe-F, and Ce-F bonds. Given that the surface hydroxyl groups played a vital role in $\mathrm{F}^{-}$removal, the possible adsorption mechanism can be described as follows.

$$
\begin{aligned}
\equiv M O H(s)+H^{+} & =\equiv M_{2} H_{2}^{+} \\
\equiv M_{2} H_{2}^{+}(s)+F^{-}(a q) & =\equiv M O F(s)+H_{2} O \\
\equiv M O H(s)+F^{-}(a q) & =\equiv M F(s)+O H^{-}
\end{aligned}
$$


where $\equiv M$ is the MFC tri-metal hydroxide.

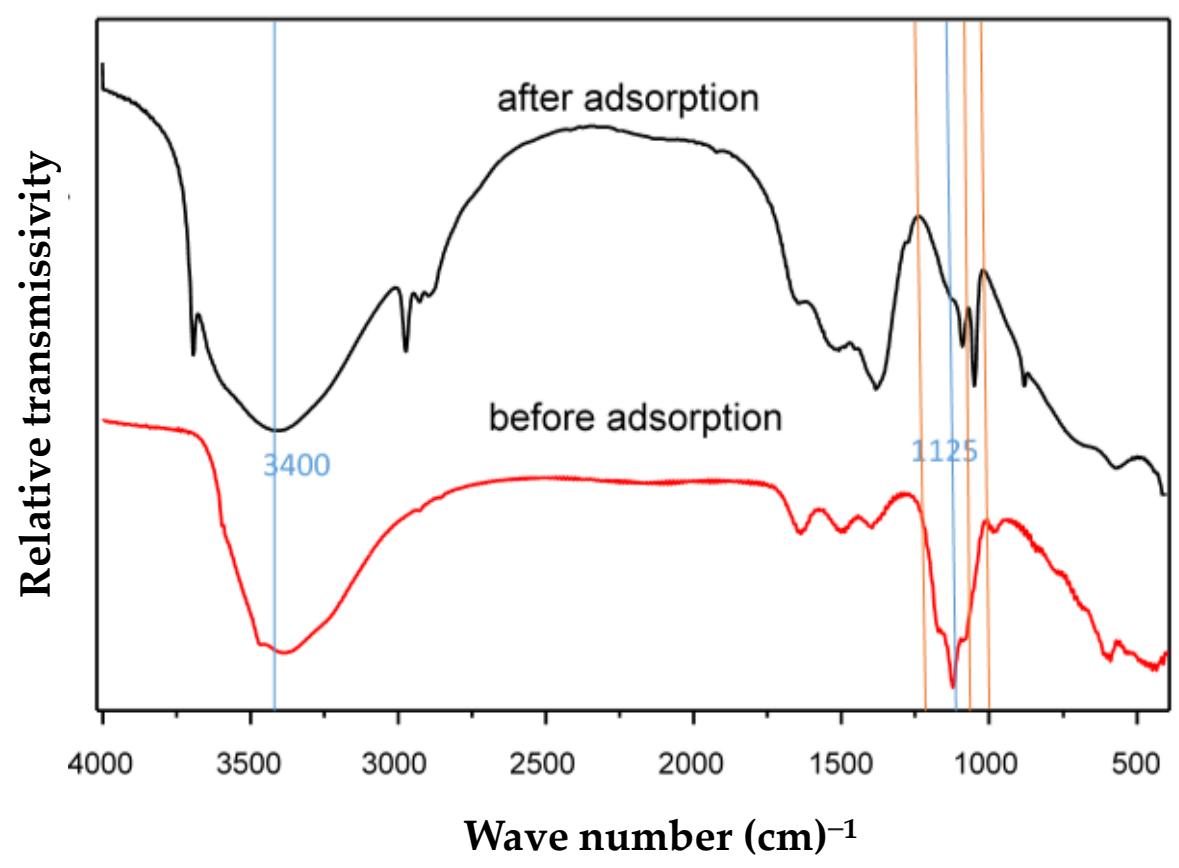

Figure 9. FTIR spectra of the MFC adsorbent.

\subsection{Adsorption Mechanisms}

The adsorption mechanism of fluoride adsorption could be obtained based on the adsorption experiments, XRD and FIIR analysis, and previous studies [25,44]. Generally, two mechanisms (i.e., electrostatic interaction and ion-exchange) can explain the fluoride adsorption of the MFC adsorbent. When the solution was in acid condition, the electrostatic interaction mainly dominated the sorption. That was because when the solution was in a lower $\mathrm{pH}$, there was more $\mathrm{H}^{+}$in the solution, which led to the protonated surface of the MFC. Meanwhile, the $\mathrm{OH}^{-}$turned into $\mathrm{OH}_{2}{ }^{+}$, which was helpful for the adsorption of $\mathrm{F}^{-}$. However, when the solution was in an alkaline condition, the ion-exchange interaction mainly dominated the sorption. That was because when the solution was in a higher $\mathrm{pH}$, there was more $\mathrm{OH}^{-}$in the solution, which possessed similar dimensions as $\mathrm{F}^{-} . \mathrm{OH}^{-}$can play an important role in not only ion-exchange interaction with $\mathrm{F}^{-}$but also competing with $\mathrm{F}^{-}$for active sites, which leads to a decrease of defluoridation capacity.

\section{Conclusions}

In this study, in order to search for an effective, safe, and environmentally friendly measure for practical engineering, a novel MFC tri-metal oxide adsorbent was developed for $\mathrm{F}^{-}$adsorption. Through the optimization of the adsorbent, preparation of the adsorbent, and experiments for the adsorbent characterization, the characterization and $\mathrm{F}^{-}$adsorption mechanism of the adsorbent were tested and analyzed. The optimum $\mathrm{pH}$ range for $\mathrm{F}^{-}$ removal was $4-5.5$, and the adsorbent was also effective at $\mathrm{pH} 7.0$ with a maximum adsorption capacity of $204 \mathrm{mg} \cdot \mathrm{g}^{-1}$, which was highly competitive compared to other reported adsorbents. The adsorption isotherm fit better with the two-site Langmuir model than the one-site model. The presences of $\mathrm{SO}_{4}{ }^{2-}, \mathrm{NO}_{3}{ }^{-}$, and $\mathrm{Cl}^{-}$had almost no effects on $\mathrm{F}^{-}$adsorption of the adsorbent. It was suitable for practical applications in groundwater with high $\mathrm{F}^{-}$adsorption with $\mathrm{F}^{-}$.

The adsorption of $\mathrm{F}^{-}$mainly occurs through ion exchange. MFC adsorbents have amorphous structures, and an exchange reaction between $\mathrm{OH}^{-}$and $\mathrm{F}^{-}$exists for enhancing the treatment capacity. The MFC tri-metal oxide adsorbent shows attractive application prospects in $\mathrm{F}^{-}$removal and can contribute to sustainable drinking water development. 
Author Contributions: Conceptualization, C.D. and X.W.; methodology, C.D. and X.W.; validation, C.D. and Z.G.; formal analysis, C.D.; investigation, C.D.; resources, X.W.; data curation, C.D.; writingoriginal draft preparation, C.D.; writing—review and editing, C.D. and M.Y.A.K.; supervision, Z.G. and P.Y. All authors have read and agreed to the published version of the manuscript.

Funding: This research was funded by the National Key Research and Development Programme of China (No.2018YFC0408102).

Institutional Review Board Statement: Not applicable.

Informed Consent Statement: Not applicable.

Data Availability Statement: Data that support the findings of this study are available from the corresponding author upon reasonable request.

Acknowledgments: Thanks to the support of the State Key Laboratory of Simulation and Regulation of Water Cycle in River Basin for proving convenient experimental conditions. The authors wish to thank the referees for providing helpful suggestions to improve this manuscript.

Conflicts of Interest: The authors declare no conflict of interest.

\section{References}

1. Jimenez-Farfan, M.D.; Hernandez-Guerrero, J.C.; Juarez-Lopez, L.A.; Jacinto-Aleman, L.F.; de la Fuente-Hernandez, J. Fluoride consumption and its impact on oral health. Int. J. Environ. Res. Public Health 2011, 8, 148-160. [CrossRef] [PubMed]

2. Ologundudu, T.O.; Odiyo, J.O.; Ekosse, G.I.E. Fluoride Sorption Efficiency of Vermiculite Functionalised with Cationic Surfactant: Isotherm and Kinetics. Appl. Sci. 2016, 6, 277. [CrossRef]

3. Jia, H.; Qian, H.; Qu, W.G.; Zheng, L.; Feng, W.W.; Ren, W.H. Fluoride occurrence and human health risk in drinking water wells from southern edge of Chinese Loess Plateau. Int. J. Environ. Res. Public Health 2019, 16, 1683. [CrossRef] [PubMed]

4. Cherukumilli, K.; Delaire, C.; Amrose, S.; Gadgil, A.J. Factors governing the performance of bauxite for fluoride remediation of groundwater. Environ. Sci. Technol. 2017, 51, 2321-2328. [CrossRef]

5. Wen, D.; Zhang, F.; Zhang, E.; Wang, C.; Han, S.; Zheng, Y. Arsenic, fluoride and iodine in groundwater of China. J. Geochem. Explor. 2013, 135, 1-21. [CrossRef]

6. Rudelis, V.; Dambrauskas, T.; Grineviciene, A.; Baltakys, K. The Prospective Approach for the Reduction of Fluoride Ions Mobility in Industrial Waste by Creating Products of Commercial Value. Sustainability 2019, 11, 634. [CrossRef]

7. Fawell, J.; Bailey, K.; Chilton, J.; Dahi, E.; Fewtrell, L.; Magara, Y.; World Health Organization. Fluoride in Drinking Water; World Health Organization (WHO): London, UK, 2006.

8. Marwa, J.; Lufingo, M.; Noubactep, C.; Machunda, R. Defeating Fluorosis in the East African Rift Valley: Transforming the Kilimanjaro into a Rainwater Harvesting Park. Sustainability 2018, 10, 4194. [CrossRef]

9. Robshaw, T.; Tukra, S.; Hammond, D.B.; Leggett, G.J.; Ogden, M.D. Highly efficient fluoride extraction from simulant leachate of spent potlining via La-loaded chelating resin. An equilibrium study. J. Hazard. Mater. 2019, 361, 200-209. [CrossRef]

10. Shen, F.; Chen, X.; Gao, P.; Chen, G. Electrochemical removal of fluoride ions from industrial wastewater. Chem. Eng. Sci. 2003, 58, 987-993. [CrossRef]

11. Chang, H.Y.H.; Kuo, Y.L.; Liu, J.C. Fluoride at waste oyster shell surfaces-Role of magnesium. Sci. Total Environ. 2019, 652, 1331-1338. [CrossRef]

12. Cai, J.G.; Zhang, Y.L.; Pan, B.C.; Zhang, W.M.; Lv, L.; Zhang, Q.X. Efficient defluoridation of water using reusable nanocrystalline layered double hydroxides impregnated polystyrene anion exchanger. Water Res. 2016, 102, 109-116. [CrossRef] [PubMed]

13. Changmai, M.; Pasawan, M.; Purkait, M.K. A hybrid method for the removal of fluoride from drinking water, parametric study and cost estimation. Sep. Purif. Technol. 2018, 206, 140-148. [CrossRef]

14. Singh, S.; German, M.; Chaudhari, S.; Sengupta, A.K. Fluoride removal from groundwater using zirconium impregnated anion exchange resin. J. Environ. Manag. 2020, 263, 110415. [CrossRef] [PubMed]

15. Camacho, L.; Torres, A.; Saha, D.; Deng, S.G. Adsorption equilibrium and kinetics of fluoride on sol-gel-derived activated alumina adsorbents. J. Colloid Interface Sci. 2010, 349, 307-313. [CrossRef] [PubMed]

16. Wu, X.M.; Zhang, Y.; Dou, X.M.; Zhao, B.; Yang, M. Fluoride adsorption on an Fe-Al-Ce trimetal hydrous oxide, Characterization of adsorption sites and adsorbed fluorine complex species. Chem. Eng. J. 2013, 223, 364-370. [CrossRef]

17. Sun, C.Z.; Qiu, J.W.; Zhang, Z.B.; Marhaba, T.F.; Zhang, Y.H. Removal of arsenite from water by Ce-Al-Fe trimetal oxide adsorbent, kinetics, isotherms, and thermodynamics. J. Chem. 2016, 1-8. [CrossRef]

18. Cai, Q.Q.; Turner, B.D.; Sheng, D.C.; Sloan, S. Application of kinetic models to the design of a calcite permeable reactive barrier (PRB) for fluoride remediation. Water Res. 2018, 130, 300-311. [CrossRef]

19. Yang, Y.; Paul Chen, J. Key factors for optimum performance in phosphate removal from contaminated water by a Fe-Mg-La tri-metal composite sorbent. J. Colloid Interface Sci. 2015, 445, 303-311. [CrossRef]

20. Farrah, H.; Slavek, J.; Pickering, W.F. Fluoride interactions with hydrous aluminum oxides and alumina. Aust. J. Soil Res. 1987, 25, 55-69. [CrossRef] 
21. Turner, B.D.; Binning, P.; Stipp, S.L.S. Fluoride removal by calcite: Evidence for fluorite precipitation and surface adsorption. Environ. Sci. Technol. 2005, 39, 9561-9568. [CrossRef]

22. Bansiwal, A.; Pillewan, P.; Biniwale, R.B.; Rayalu, S.S. Copper oxide incorporated mesoporous alumina for defluoridation of drinking water. Microporous Mesoporous Mater. 2010, 129, 54-61. [CrossRef]

23. Dong, S.; Wang, Y. Characterization and adsorption properties of a lanthanum-loaded magnetic cationic hydrogel composite for fluoride removal. Water Res. 2016, 88, 852-860. [CrossRef] [PubMed]

24. Thathsara, S.K.T.; Cooray, P.L.A.T.; Mudiyanselage, T.K.; Kottegoda, N.; Ratnaweera, D.R. A novel Fe-La-Ce tri-metallic composite for the removal of fluoride ions from aqueous media. J. Environ. Manag. 2018, 207, 387-395. [CrossRef] [PubMed]

25. Huang, S.M.; Hu, M.L.; Li, D.; Wang, L.P.; Zhang, C.; Li, K.; He, Q.Q. Fluoride sorption from aqueous solution using Al(OH)(3)modified hydroxyapatite nanosheet. Fuel 2020, 279, 118486. [CrossRef]

26. Kumar, R.; Sharma, P.; Aman, A.K.; Singh, R.K. Equilibrium sorption of fluoride on the activated alumina in aqueous solution. Desalin. Water Treat. 2020, 197, 224-236. [CrossRef]

27. Ghorai, S.; Pant, K.K. Investigations on the column performance of fluoride adsorption by activated alumina in a fixed-bed. Chem. Eng. J. 2004, 98, 65-173. [CrossRef]

28. George, S.; Pandit, P.; Gupta, A.B. Residual aluminium in water defluoridated using activated alumina adsorption-Modeling and simulation studies. Water Res. 2010, 44, 3055-3064. [CrossRef]

29. Wu, X.M.; Zhang, Y.; Dou, X.M.; Yang, M. Fluoride removal performance of a novel Fe-Al-Ce trimetal oxide adsorbent. Chemosphere 2007, 69, 1758-1764. [CrossRef]

30. Tor, A.; Danaoglu, N.; Arslan, G.; Cengeloglu, Y. Removal of fluoride from water by using granular red mud, batch and column studies. J. Hazard. Mater. 2009, 164, 271-278. [CrossRef]

31. Wu, L.Y.; Zhang, G.K.; Tang, D.D. A novel high efficient Mg-Ce-La adsorbent for fluoride removal, kinetics, thermodynamics and reusability. Desalin. Water Treat. 2016, 57, 23844-23855. [CrossRef]

32. Zhou, J.; Zhu, W.K.; Yu, J.; Zhang, H.P.; Zhang, Y.D.; Lin, X.Y.; Luo, X.G. Highly selective and efficient removal of fluoride from ground water by layered Al-Zr-La Tri-metal hydroxide. Appl. Surf. Sci. 2018, 920-927. [CrossRef]

33. Chi, Y.L.; Chen, Y.T.; Hu, C.L.; Wang, Y.S.; Liu, C. Preparation of Mg-Al-Ce triple-metal composites for fluoride removal from aqueous solutions. J. Mol. Liq. 2017, 242, 416-422. [CrossRef]

34. Li, L.; Zhu, Q.; Man, K.X.; Xing, Z.P. Fluoride removal from liquid phase by Fe-Al-La trimetal hydroxides adsorbent prepared by iron and aluminum leaching from red mud. J. Mol. Liq. 2017, 237, 164-172. [CrossRef]

35. Kabir, H.; Gupta, A.K.; Debnath, D. Synthesis, optimization and characterization of mesoporous Mg-Al-Fe tri-metal nanocomposite targeting defluoridation, Synergistic interaction of molar ratio and thermal activation. J. Mol. Liq. 2018, 268, 376-385. [CrossRef]

36. Ghosh, A.; Chakrabarti, S.; Biswas, K.; Ghosh, U.C. Column performances on fluoride removal by agglomerated Ce(IV)-Zr(IV) mixed oxide nanoparticles packed fixed-beds. J. Environ. Chem. Eng. 2015, 3, 653-661. [CrossRef]

37. Ramos-Vargas, S.; Alfaro-Cuevas-Villanueva, R.; Huirache-Acuna, R.; Cortes-Martinez, R. Removal of fluoride and arsenate from aqueous solutions by aluminum-modified guava seeds. Appl. Sci. 2018, 8, 1807. [CrossRef]

38. Raichur, A.M.; Basu, M.J. Adsorption of fluoride onto mixed rare earth oxides. Sep. Purif. Technol. 2001, 24, 121-127. [CrossRef]

39. Zhou, Y.M.; Yu, C.X.; Shan, Y. Adsorption of fluoride from aqueous solution on La ${ }^{3+}$-impregnated cross-linked gelatin. Sep. Purif. Technol. 2004, 36, 89-94. [CrossRef]

40. Chen, L.; Wang, T.J.; Wu, H.X.; Jin, Y.; Zhang, Y.; Dou, X.M. Optimization of a Fe-Al-Ce nano-adsorbent granulation process that used spray coating in a fluidized bed for fluoride removal from drinking water. Powder Technol. 2011, 206, 291-296. [CrossRef]

41. Adak, M.K.; Sen, A.; Mukherjee, A.; Sen, S.; Dhak, D. Removal of fluoride from drinking water using highly efficient nanoadsorbent, Al(III)-Fe(III)-La(III) trimetallic oxide prepared by chemical route. J. Alloy. Compd. 2017, 719, 460-469. [CrossRef]

42. Xu, Y.M.; Ning, A.R.; Zhao, J. Preparation and defluoridation performance of activated cerium(IV) oxide/SiMCM-41 adsorbent in water. J. Colloid Interface Sci. 2001, 235, 66-69. [CrossRef] [PubMed]

43. Ho, Y.S.; McKay, G. Pseudo-second order model for sorption processes. Process. Biochem. 1999, 34, 451-465. [CrossRef]

44. Onyango, M.S.; Kojima, Y.; Aoyi, O.; Bemardo, E.C.; Matsuda, H. Adsorption equilibrium modeling and solution chemistry dependence of fluoride removal from water by trivalent-cation-exchanged zeolite fluoride ion. J. Colloid Interface Sci. 2004, 279, 341-350. [CrossRef] [PubMed]

45. Liu, H.; Deng, S.B.; Li, Z.J.; Yu, G.; Huang, J. Preparation of Al-Ce hybrid adsorbent and its application for defluoridation of drinking water. J. Hazard. Mater. 2010, 179, 424-430. [CrossRef] [PubMed]

46. Kumar, E.; Bhatnagar, A.; Ji, M.; Jung, W.; Lee, S.H.; Kim, S.J.; Lee, G.; Song, H.; Choi, J.Y.; Yang, J.S.; et al. Defluoridation from aqueous solutions by granular ferric hydroxide (GFH). Water Res. 2009, 43, 490-498. [CrossRef]

47. Viswanathan, N.; Sundaram, C.S.; Meenakshi, S. Sorption behaviour of fluoride on carboxylated cross-linked chitosan beads. Colloid Surf. B 2009, 68, 48-54. [CrossRef] 